\title{
Remembering False Memories: Insights from DRM Studies
}

\author{
Patrycja Maciaszek
}

Institute of Psychology, Pedagogical University of Cracow, Poland

Copyright $\mathrm{C} 2018$ by authors, all rights reserved. Authors agree that this article remains permanently open access under the terms of the Creative Commons Attribution License 4.0 International License

\begin{abstract}
The issue of how certain we could be about our memory and the accuracy of its content draws researchers' attention for decades. Still, as the new data appears, the question remains important, especially on fields of cognitive and social psychology. Presented research focuses on creation of laboratory- evoked false memories that demonstrate high level of certainty of "remembering" declared by participants. Thus, the main aim of presented studies was to establish whether false memories are transferred from semantic memory, where they are believed to appear into the episodic memory. It was assumed that recollecting memories, as well true as false, is connected with increasing level of activation in a very specific part of memory network within semantic memory magazine. It was crucial to (1) investigate if similar effect appears regarding to false episodic memories and (2) verify whether the laboratory-created false memories behave rather like true memories instead of random mistakes. Hypothesis were verified using the Deese-Roediger-McDermott (list-of- words-related, DRM) paradigm and remember-know judgment procedure. Study conducted on 61 Jagiellonian University students shown that participants reported more often remembering both: true and false memories (contrary to unrelated mistakes). Moreover, medium level of properly recollected words (57\%) was approximate to medium level of false memories $(52 \%)$. Such results showed that effect of memory transfer between semantic and episodic memory magazines occurred, and that laboratory-evoked false memories engage "the feeling of remembering" events that never occurred.
\end{abstract}

Keywords Memory, Semantic, Episodic, False Memories, DRM Paradigm, Feeling of Remembering, Remember Judgment, Confidence Judgments

\section{Introduction}

Problems concerning the formation of memory traces, including bequests of events which did not take place in the reality (false memories, FM), occupies attention of psychologists representing various research perspectives from early 1930' (Bartlett, 1932). In a modern manner this subject matter is dynamically developed both aground the cognitive psychology (Roediger et. al., 2014; Pohl, 2012b; Gallo, 2010), the neuropsychology (Arndt, 2012a, 2012b; Fuentemilla et. al., 2009; Atkins and Reuter-Lorenz, 2008), as social psychology (Klatzky, 2014; Loftus et. al., 2010, 2013; Lenton, Blair \& Hastie, 2001). One of the popular methods that enable to measure the magnitude of FM occurrence is the DRM procedure (Deese-Roediger-McDermott paradigm, 1959, 1995), which contains presentation several lists of semantically related words related and a memory test to evaluate participants' recognitions accuracy. It is expected that participants recollect some of the words presented during the first stage of an experiment, but also a number of non-presented, highly semantically related items, which are considered as false memories (Monds et. al., 2013). Such a design permits both the precise evaluation of the FM phenomenon scale in general, as well as sizes of the effect at individual units (Martial \& Dehon, 2015; Watson et. al., 2005). Moreover, as the ecological accurateness for this method remains satisfying, the results obtained from studies with use of DRM enable not only to evaluate the magnitude of FM effect (precisely: how many false memories does the individual create), but also provides possibility to access how certain people tend to be when it comes to recall memory content - true, as well as false. Also, the use of this method enables to evaluate how certain people tend to be when it comes to recall memory content, by assessing individual remembering experience.

False memories (FM) are commonly defined as remembering by individuals events that never happened or remembering them differently from the way they occur in reality (Roediger \& McDermott, 1995). Thus, the purpose of presented study is to enrich existing knowledge by providing comprehensive research focused on of subjective sense of remembering FM, experienced and reported by individuals. Additionally, the feeling of certainty due to 
particular recollections in relation to memory accuracy (ACC) has been examined. Characterizing FM across the indication of the way, into which they are encoded and stored in the memory and comparing it to (1) correct recollections and (2) random errors arising in the memory on the field of " feeling of remembering" declared by individuals and the level of certainty they present, would allow to achieve better understanding the false memory phenomenon in general. Current work aims to establish the degree to which mechanisms responsible for correct and incorrect recollections remain mutual (Mather, Henkel, \& Johnson, 1997). In general it is claimed that the high level of the certainty accompanies correct recollections, basing on the feeling of remembering specific details of precise situation (remembering), in opposition to the feeling of the acquaintance (familiarity) tied with less precise evaluations, related rather to the feeling that 'something happened' than recalling the actual memory trace (Mather, Henkel \& Johnson, 1997; Pohl, 2012, Arndt, 2012a; Schacter, 2001). Following this way of thinking, in present research it was expected to observe that individuals making more remember-judgments, compared to those preferring know-judgments (Tulving, 1985; Gardiner \& Java, 1993), would be less susceptible to FMs. Their memory was assumed to be more exact, accompanied by high level of the certainty in relation to the memory of the source of information (Frithsen \& Miller, 2014 Tulving \& Craik, 2000).

Studies conducted on the field of experimental psychology, focused on the subjects' experience of certainty to - respectively - true and false memories, and it's relation to random mistakes remain incoherent and lead to incompatible conclusions thus far. According to Loftus et.al. (2010, 2013) individuals convinced about the accurateness events they remembered, in fact demonstrate higher susceptibility to a various memory distortions, including not only FM vulnerability, but also tendency to undergoing suggestion, misinformation effect or imagination inflation In turn, Alberts (2010) demonstrates that all the effects related to intensification of the susceptibility are bounded to basic cognitive processes efficiency. Also, he points out that subjects' conviction about the correctness of false memory traces comes as a result of the weak inhibition control among working memory and attentional processes.

To the ambiguity of previous results, the experiment aiming to establish the relationship between magnitude of FM effect and the occurrence of "feeling of remembering" (which manifests as a strong, subjective conviction of FM accuracy) among participants judgments, was conducted.

Additionally, it was hypothesized - in compliance with Collins and Loftus (1975) theory of the automatic activation spread through the semantic memory network false memories would demonstrate similar characteristic to proper recollections. As the ground research in DRM paradigm shows, FMs arise at the very early stage of remembering process (encoding) and as soon as they once appear, they are being clustered to true ones as a full-right, regularly remembered memory trace (Maciaszek, 2015).

\section{Theoretical Basics}

The memory network. The distinction between semantic and episodic memory defines semantic memory as a hierarchically organized, but flexible structure network, composed of nodes (representing notions) and relations between them (Tulving, 1972).

Memorizing information results from the activation of particular nodes, which may originate from internal or external sources, therefore activation may be raised not only by stimulating the particular node of the memory network, but also may automatically spread from one node to another, spilling to strongly connected node without any direct activation (Nelly, 1977; Posner \& Snyder, 1975). The acquisition of new information that is immediately incorporated into the network might enrich existing structure although once it happened, providing any changes into an existing nodes and their connection remains not an easy task (Collins and Quillian, 1969). The probability of retrieval of specific node depends on the initial strength of activation, which achieves greater rates for strongly linked nodes, i.e. the distance between nodes and the role of semantic proximity in estimating the likelihood of retrieving a memory appear worth investigating. The implications of the described mechanism are vast, as it is believed to be responsible for memorizing not only true, but also additional, highly related pieces of information.

According to Tulving's theory, different structure was attributed to episodic memory, which contains selectivity gathered information of events from the individuals past, arranged over the timeline, characterized by the strong dependence on the context. The last from the enumerated features makes episodic traces extremely vulnerable to changes, concerning those that are evoked internally, arising as a result of reconstruction processes among memory. What's worth to emphasize about this process is that it is only partially based on a truly remembered events, which makes memory vulnerable to externally influential factors (such as suggestion), well-known to possibly impact its content (for a review, see: Loftus, 2005).

The aim of the present work was to focus on the specific memory distortions, appearing at the stage of encoding. Presumably, every recollection of criterion-specific memory data initializes multiple operations that finally lead to overwriting and reinterpreting the original memory trace, changing it one step at a time. Thus, at the end, the initial memory trace surrenders to upcoming modifications, which not only disfigure it, but also keep people convinced about accuracy of their memory (see also: Schacter, 1996).

The distinction between semantic and episodic memory is crucial for current research: recalling the semantic data should not affect the semantic memory content, because its structure makes it highly change-resistant, contrary to 
episodic memory, which is extremely vulnerable to any kind of distortion (Craik \& Tulving, 2000).

False memories. False memories, commonly defined as events (or only some elements of them) that - despite being stored in the memory - didn't take place in the reality. Accordingly, FM appears as a kind of disorder among correct memory operations and results in false recognition of non-presented stimuli (words, geometrical figure, photo etc.), accompanied by a high level of certainty (Schacter \& Slotnik, 2004). However there is no consentaneous explanation on how it is possible for FM to occur yet, at least few facts remain established. FMs, by their semantic proximity to regular ones, are incorporated into the memory of true events, which makes both technically undistinguishable. At this point, it is required to emphasize the difference between false memories - as a specific phenomenon - and more general memory mistakes, concerning random errors committed by accident, or as a result of other variables. FM occurrence demonstrates several regularities, thanks to which their occurrence become predictable; their outline remains foreseeable, as a consequence of human mind architecture (Pohl, 2012). What is also observed, importantly for the recent study findings, remembering FMs is followed by the strong certainty of this recollection (resulting from already mentioned 'feeling of remembering' Jerofiejew, 2005; Loftus, 2003; Hashtroudi \& Lindsay, 1993). To sum up, false memories - instead of common mistakes - share crucial features with true ones (Monds et. al., 2013). Activation spreading through the memory network is believed to be one of the mechanisms underlying FM creation (Collins and Loftus, 1975). Compellingly, differences between both semantic and episodic memory 'storages' mentioned above were already proven with number of neuroimaging studies (e.g. Garoff-Eaton, Slotnick \& Schacter, 2005; Englert, Wentura, 2016). In general, it is established that recollecting elements from semantic and episodic memory causes different patterns of brain activation. Thereby, one may hypothesize about the occurrence of the effect of the transfer: false memories are carried by rote semantic in which - how indicates the most of theoreticians - arise, to the episodic memory, where takes place the consolidation of false memory traces and their integration with the cognitive representation of the original situation. As an effect, FMs became indiscernible from true ones.

Subjective certainty. The subjective certainty might be described as a strong, grounded belief reported by individuals, that some events not only took place but also are claimed to be clearly remembered (Aronson \& Tavris, 2008; Loftus, 2005). In order to provide credible measurement for magnitude of this phenomena, "remember-know judgment" procedure is widely applied (Tulving 1972, 1985; Gardiner \& Java, 1991), as it requires not only detecting discrepancy between true (correct) and incorrect memory traces, but also the identification of their source. Researchers conform that the feeling of remembering, described at times as ,the feeling of the authenticity" (Weingardt et. al., 1995) under the forced distinction condition is a reliable indicator of the episodic memory trace appearance. For example, Marini and co-workers (2012) point out that remember-judgments often appear when individual is capable to memorize specific, detailed characteristics of particular situation, opposite to know-judgments, characteristic for more fuzzy feeling of familiarity, underlying decision based on weakly specified conviction that "something happened", with lack of perceptual details supporting such feeling.

In research using the DRM-procedure know-judgments are typical for incorrect recognitions of random words, while remember-judgments often occur for both: true (correct) and false (closely related to true) memories (Gallo, 2006, 2013). This paper aims at verifying the hypothesis that remembered-judgments for FM would appear substantially more often than know-judgments. Also, it was expected to observe similar proportion of remembered-know judgments for false memories and correct recollections, compared to random memory mistakes.

\section{Method}

Participants. 61 undergraduate students in age of 19-23 $(\mathrm{M}=21.8 ; \mathrm{SD}=1.17)$ participated ( 24 men and 37 women $)$. No salary for participation was provided.

Materials. 8 DRM lists of related words, developed to elicit FM effect were presented to participants. Previously, polish adaptation of DRM procedure was prepared, along with experiments that replicated the original study findings (Maciaszek, 2013, 2014; Olszewska and Ulatowska, 2013). Reported experiment includes exposing participants to 8 lists of words, 15 words each list. Every of 8 lists were designed to evoke intrusion of 1 non-presented, but strongly related to presented word (critical lure, CL). Afterwards, during the testing phase of the experiment, participants were expected to recollect presented words as well as CLs (which are considered as false memories, see: Monds et. al., 2013; Atkins \& Reuter-Lorenz, 2008), as a consequence of semantic proximity, in compliance with the activation-spread theory (Collins \& Loftus, 1975).

The test of the memory had a form of recognition and consisted of 48 words, which could be divided into one of three categories: presented (truly shown on previous part; they are basic to generate true memories), critical lures (not presented, but strongly semantically related to the theme of the list they are basic to generate false memories) and non-presented (non-related to the theme of the list recognition of such word was considered as committing a random mistake). Participants' task was to choose which words - in their opinion - were showed on the stage of the presentation (words in the test of the memory were chosen from all lists) and - additionally - to the words, they chose make remember-know judgments. It is proper to specify 
that entire test contains 48 items: 24 words truly shown during the earlier phase of the experiment, 8 critical lures (the tool was constructed so that every list had been able to cause intrusion of one $\mathrm{CL}$, turning into FM while memory proceeds with semantics) and non-presented 16 words. In order to assess "sense of remembering" forced distinction (remember-know judgment) was comprised into the procedure (DeSoto \& Roediger (2014).

Procedure. The study was conducted in the Institute of Psychology of Jagiellonian University laboratories. Participants were informed about taking part in a study dedicated to investigate memory efficiency and signed an agreement. Afterwards, they were instructed to focus their attention to stimuli presented on a computer screen and memorize as many as possible. After ascertaining participants understood instruction to follow it during the experiment, they were allowed to run the DRM-RK procedure (individually, with power-point presentation prepared previously).

At the first stage, list of words were shown sequentially on a computer screen (1500 ms for one word). Words within each of 8 lists were chosen by their semantic proximity: every list has it' own "theme". 15 highly related words were presented to participants during each DRM list, followed by distraction task - simple mathematical equation, e.g., $(3 * 8)-5=18$ ", that demands to make a decision whether is it true or false?). Time for this the decision was limited to 1 minute, after which the presentation of another list of words related began, and the procedure starts over again (during the entire experiment 8 times). At the second part of the study, participants received a memory test (constructed as described above) and their task was to distinguish words presented on lists during the previous stage from non-presented items, which include both: non-related word (random mistakes) as well as semantically associated items (critical lures) considered as false memories, whether recognized by participants. 48-words memory test was printed on a sheet of paper and given to participants for 2 minutes. Additionally, after deciding whether each word was presented or not, participants were asked to declare to claim whether they remember the exact moment of word's occurrence during the presentation (in this case the "remember judgment" should be made). Otherwise, if participant declared rather feeling that the word was presented, but wasn't able to recall the moment of presentation precisely, the "know judgment" should be made. Detailed scheme of experiment presents figure 1 .

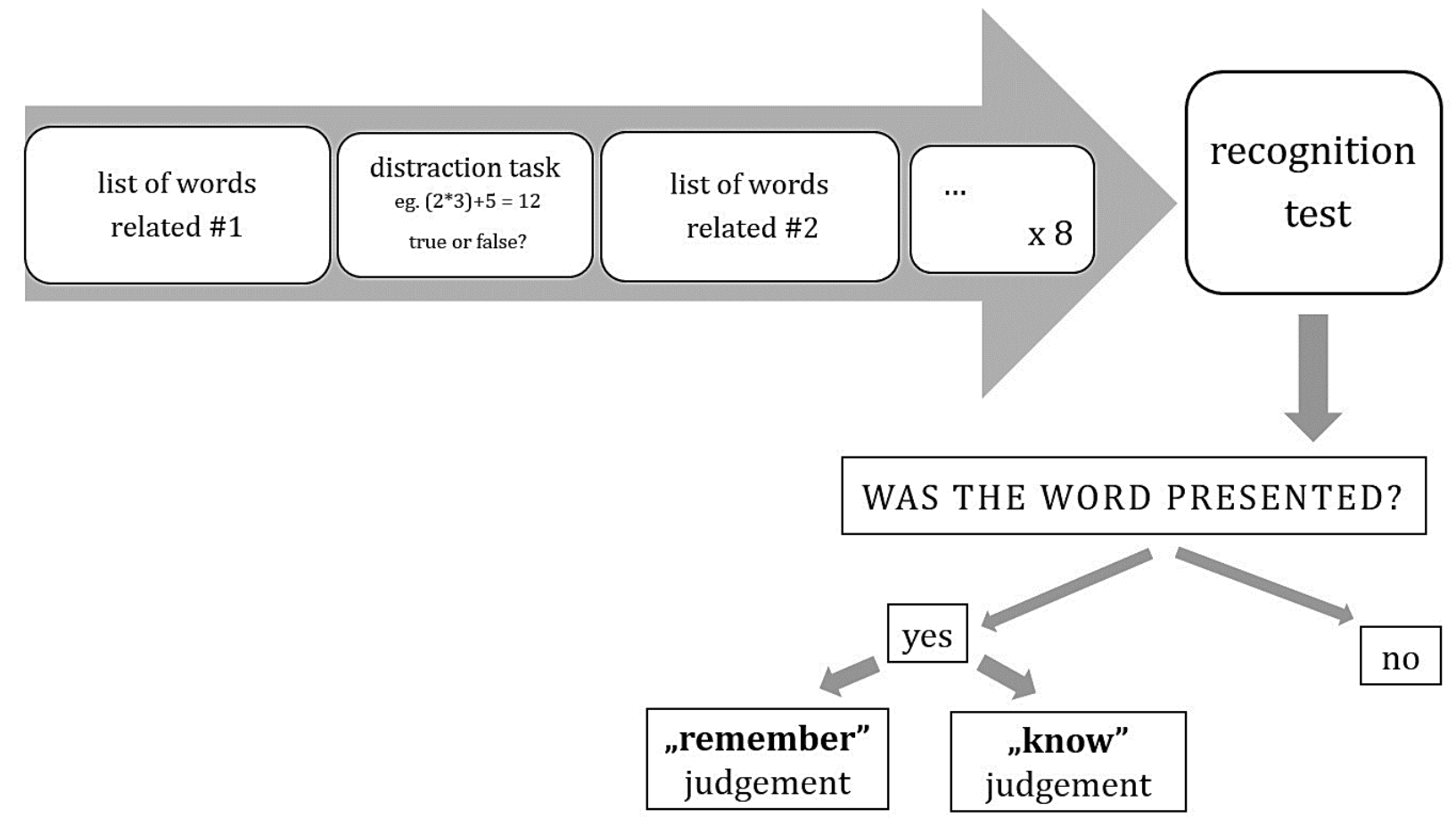

Figure 1. The design of the experiment 


\section{Results}

It turned out that critical lures comprised fairly $29 \%$ of all the recollections made by participants, basing on remember-judgments $(\mathrm{M}=0.29 ; \mathrm{SD}=0.12)$. Considering the construction of the memory test, such result should be acknowledged as very high (the test consisted 48 words, whereof $24(50 \%)$ constituted correct words, 16 (33\%) incorrect and 8 (17\%) critical concepts).

It was also surprising to notice that participants made the 'remember judgment' above the half $(52,2 \%)$ of the maximum number of critical lures $(\mathrm{M}=0.52 ; \mathrm{SD}=0.23)$. To compare, this proportion remained similar for presented words (correct recollections judged as "remembered" at the level of 57\%) and differ dramatically for non-presented words (memory mistakes) - the declaration of 'remembering' was made only due to $9,4 \%$ of them.

What is more, CLs were recognized as ,remembered” 1,36 times more often than "known", while for random mistakes this index stands at the level of 0.35 (for correct words $-2,13$, respectively).

Thus, obtained results allow to support hypothesis about CL transfer from semantic memory (where they are produced, at least in DRM procedure) to episodic memory storage, (which contains full representations of life-situations that individual remember). Accordingly, each participant undertaking DRM procedure, to meet the study design demands, needed to relocate his memory content from semantic to episodic representation and consequently - create some vivid false memories for presentation of non-presented critical lures. Table 1 demonstrates obtained results, with special attention paid to the magnitude of FM effect.

Table 1. Proportion of recognitions made by participants due to presented, non-presented words and critical lures (CL), by "remember" and "know" judgments.

\begin{tabular}{|c|c|c|c|c|}
\hline $\begin{array}{c}\text { recognition / } \\
\text { judgment }\end{array}$ & \multicolumn{2}{|c|}{ remember } & \multicolumn{2}{c|}{ know } \\
\hline & $\mathrm{M}$ & $\mathrm{SD}$ & $\mathrm{M}$ & $\mathrm{SD}$ \\
\hline presented & .56 & .02 & .29 & .21 \\
\hline non-presented & .09 & .00 & .67 & .45 \\
\hline $\mathrm{CL}$ & .52 & .04 & .33 & .35 \\
\hline
\end{tabular}

What also seem interesting, is the strong positive correlation revealed between the number of words judged by participants as "known" and the total number of recalled words $(r=0.69 ; \mathrm{p}<0.001)$. Such a result stays in line with other findings presented in this paper, suggesting that random memory errors (recognitions of non-presented, not-associated words) were linked to the feeling of familiarity (know-judgment), declared by participants. In opposite, recognition of presented word and related, non-presented critical items, were regularly accompanied by remember-judgment. Similar conclusions come from investigating the correlation matrix, i.e. strong relations were detected among the summary number of all errors committed by participants (non-presented words recognitions) and the total number of mistakes followed by the know-judgment $(\mathrm{r}=0.66 ; \mathrm{p}<0,001)$ (for details - see: table 2).

Table 2. Correlation matrix for all the variables collected in Experiment 1.

\begin{tabular}{|c|c|c|c|c|c|c|c|c|c|}
\hline & $\mathrm{CL}$ & $\mathrm{CL}-\mathrm{R}$ & CL-K & $\begin{array}{c}\text { presented } \\
\text { words }\end{array}$ & $\begin{array}{l}\text { presented } \\
\text { words-R }\end{array}$ & $\begin{array}{l}\text { presented } \\
\text { words-K }\end{array}$ & $\begin{array}{l}\text { non-presented } \\
\text { words }\end{array}$ & $\begin{array}{l}\text { non-presented } \\
\text { words-R }\end{array}$ & $\begin{array}{c}\text { non-presented } \\
\text { words-K }\end{array}$ \\
\hline $\begin{array}{l}\text { all recollected } \\
\text { words }\end{array}$ & $.795 * * *$ & $.539 * * *$ & $.301 *$ & $.852 * * *$ & $.684 * * *$ & .153 & $.609 * * *$ & $.363 * *$ & $.558 * * *$ \\
\hline $\mathrm{R}$ (all) & $.676^{* * *}$ & $.619 * * *$ & .046 & $.765^{* * *}$ & $.888 * * *$ & $-.338 * *$ & $.333 * *$ & .170 & $.326^{*}$ \\
\hline K (all) & $.328 * *$ & -.049 & $.478 * * *$ & $.275^{*}$ & -.137 & $.667 * * *$ & $.658 * * *$ & $.491 * * *$ & $.530 * * *$ \\
\hline CL & 1 & $.695 * * *$ & $.357 * *$ & $.641 * * *$ & $.519 * * *$ & .118 & $.300 *$ & .200 & $.260 *$ \\
\hline CL-R & $.695^{* *}$ & 1 & $-.424 * *$ & $.386^{* *}$ & $.448 * * *$ & -.170 & $.255^{*}$ & .027 & $.325 *$ \\
\hline CL-K & $.357^{* *}$ & $-.424 * *$ & 1 & $.306^{*}$ & .072 & $.371 * *$ & .046 & .217 & -0.95 \\
\hline $\begin{array}{l}\text { presented } \\
\text { words }\end{array}$ & $.641 * * *$ & $.386 * *$ & $.306^{*}$ & 1 & $.816^{* * *}$ & .160 & .160 & .024 & .199 \\
\hline $\begin{array}{l}\text { presented } \\
\text { words-R }\end{array}$ & $.519 * * *$ & $.448 * * *$ & .072 & $.816^{* * *}$ & 1 & $-.436 * * *$ & .099 & -.084 & .195 \\
\hline $\begin{array}{c}\text { presented } \\
\text { words-K }\end{array}$ & .118 & -.171 & $.371 * *$ & .160 & $-.436 * * *$ & 1 & .065 & .171 & -.037 \\
\hline $\begin{array}{l}\text { non-presented } \\
\text { words }\end{array}$ & $.300 *$ & $.255^{*}$ & .046 & .160 & .099 & .065 & 1 & $.688^{* * *}$ & $.849 * * *$ \\
\hline $\begin{array}{c}\text { non-presented } \\
\text { words-R }\end{array}$ & .200 & .027 & .217 & .024 & -.084 & .171 & $.688 * * *$ & 1 & .200 \\
\hline $\begin{array}{c}\text { non-presented } \\
\text { words-K }\end{array}$ & $.260 *$ & $.325 *$ & -.095 & -.199 & -.195 & -.037 & $.849 * * *$ & .200 & 1 \\
\hline
\end{tabular}

Note: ${ }^{*} \mathrm{p}<0.05 ; * * \mathrm{p}<0.01, * * * \mathrm{p}<0.001 ;$

„CL" refers to the number of all critical lures recollected by participants; “CL-R" - means number of lures judged as remembered and "CL-K”-known. Other variables we marked similarly. 


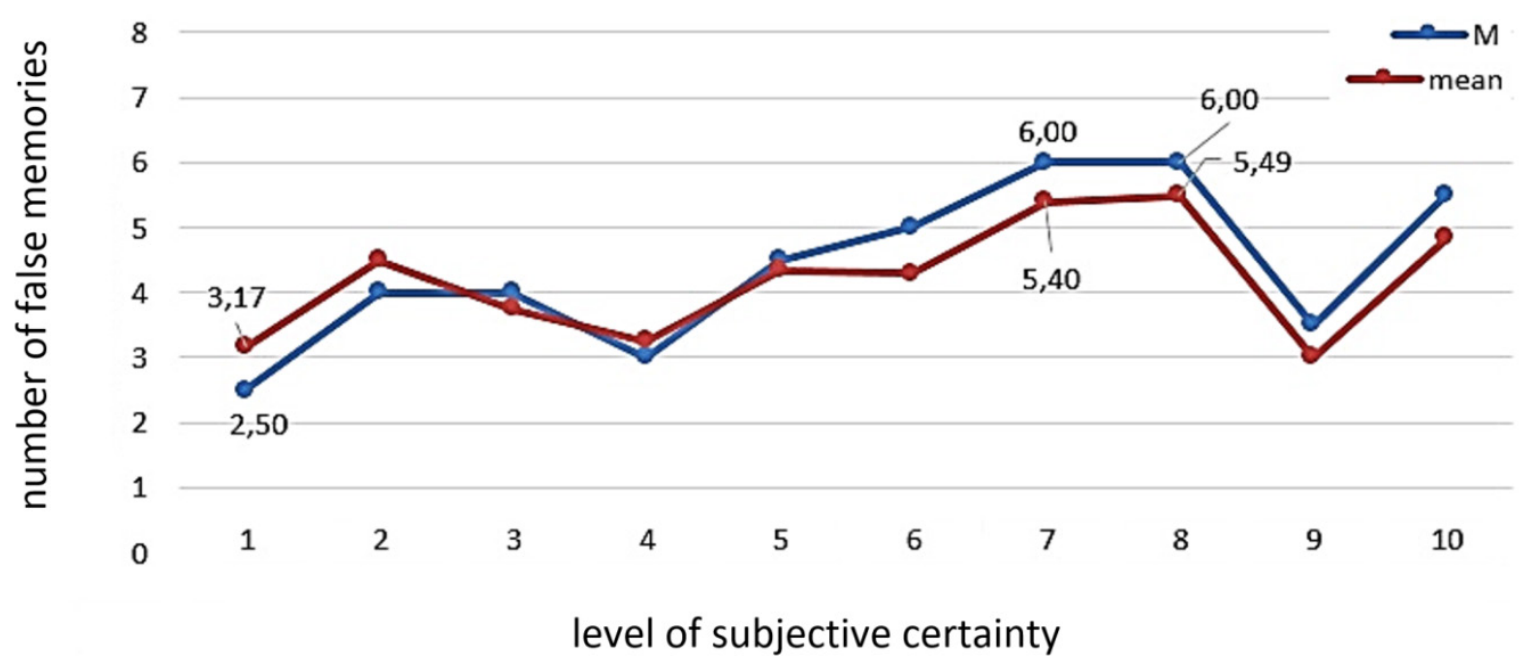

Note: Participants were indexed by $\mathrm{R} / \mathrm{K}$ judgments proportion.

Figure 2. The relationship between certainty of remembering, measured by the proportion of remember-know answers to false memory rates.

No saliences were detected between mean number of recollections for presented words (true memories) and critical lures (false memories) $(\mathrm{t}(60)=-1.87 ; \mathrm{p}=0.066)$. In turn, the difference between CLs and non-presented words (random mistakes) was revealed $(\mathrm{t}(60)=14,80 ; \mathrm{p}<0,001)$, both at the general level concerning all the recollected items, and detailed analysis, which includes comprehensive comparison of remember-know judgments for all of the items used in presented experiment. The mean number of recollections made by participants to critical lures and non-presented items revealed significant differences (respectively, $\mathrm{t}(60)=5.36, \mathrm{p}<0.0001$ for the know-judgment and $\mathrm{t}(60)=-9.03, \quad \mathrm{p}<0.0001$ for the remember-judgment). Therefore, as the pattern of results remains stable, previous assumptions were confirmed. FM of CLs is stored and proceeded within memories in the way close to presented words, and completely different from random errors (non-presented items). Such result demonstrated the phenomenon of the specific transfer from semantic to episodic memory - act of recollecting triggers automatic activation of the memory network, which spreads not only into truly remembered pieces of events but also - whether strong enough - involves items close-by (CL turning into FM in present study). As an effect, both became memorized and recalled in an analogous way, among episodic bequests of entire event.

Moreover, previous study findings allowed us to set the question whether there is a detectible relationship between tendency to create FM and subjective sense of certainty due to memory content (Maciaszek, 2015). Post-hoc data analysis revealed such differences $(\mathrm{F}(51,9)=11,74$; $\mathrm{p}<0,001)$. Also, the number of FMs varied among individuals showing different levels of certainty, defined as proportion of remember-know judgments (Jacoby, 1991; Rajaram, 1993; DeSoto \& Roediger, 2014) (see: fig. 2).

Participants were indexed by the proportion of $\mathrm{R} / \mathrm{K}$ judgments they made. Based on the degree of declared certainty, 10 groups were created. Subjects demonstrating the highest proportion of $\mathrm{R} / \mathrm{K}$ judgments (which is a common method to measure recollection certainty, resulting from sense of remembering particular event) were assigned as "tens". Consequently, "ones" were subjects with the lowest level of certainty. Obtained result revealed that individuals demonstrating higher level of certainty are more susceptible to creating false memories. Conducting more detailed analysis enabled to establish that participant showing the high levels of certainty due CL recollections (maximum value of $\mathrm{R} / \mathrm{K}$ indicator, granting the greater number of the answer remember in relation to know) were more susceptible to create FM, compared to less certain ones (preference of making rather know than remember judgments due to CL). Saliencies were detected among group 1 (the lowest level of the certainty, with the average number of FM at the level of $M=2,5)$, and with groups 7 and 8 (the high level of the certainty, accompanied by the average number of FM for both groups at the level of $M=6$ ) - $\mathrm{NIR}=-2.12, \quad \mathrm{p}<0,05$ and $\mathrm{NIR}=-2.29, \quad \mathrm{p}<0,05$, respectively.

\section{Discussion}

Presented study was dedicated to verify the hypothesis concerning the FM transfer among the memory network. It was assumed that laboratory-evoked FM are produced by free activation spread among the semantic network, which results in blending them together with true ones and transferring into the episodic memory, as fully-fledged, accompanied by a feeling of remembering memory traces. As an effect of such process memory would contain as well true as false traces of the events did not ever happen. Such conclusions remain coherent with other researchers' findings, i.e. Sergi et. al. (2014) proved that the time of delay is not related to the number of FM arising at memory 
test on DRM procedure, which suggests the transfer must be immediate. Similar results were achieved by Atkins \& Reuter-Lorenz (2008) and Tse \& Neely (2005).

Although the creation of false memories could be explained with the automatic spread of activation down the memory network, lack of advantage in ability to distinguish true and false memories for individuals preferring remember judgments, suggests a necessity to look for a broader explanation. Several research points at reporting "remembering" something by participant as an undisputable marker of episodic memory trace (cf. Yonelinas, 2001). Therefore, one may consider how is it possible to achieve such results within semantic memory? However, the results of conducted study enroll into the research stream of led consistently for many years ' 90 , corresponding simultaneously with modern exploratory trends, it also puts some relevant issues under further consideration (Roediger and McDermott, 1995, Dehon, 2012; Wiesmann and Ishai, 2008; Mickes, Travis and Wixted, 2013; Gallo, 2013).

The experimental procedure was also designed to examine whether the occurrence of so-called sense of remembering, well-known as a reliable subjective certainty rate, is somehow related to the magnitude of FM effect among individuals' recollections (Jacoby, 1991; Rajaram, 1993; DeSoto \& Roediger, 2014). Obtained results allow to ascertain that people not only remember experimentally implemented false memories with similar probability to the true ones (respectively; $52 \%$ and $56 \%$ ), but also experience strong certainty due to false recollections, expressed by tendency to judge them as remembered, in opposition to random mistakes, commonly supposed to be known. Thus, propose explanation for this phenomenon refers to existence different mechanisms responsible for the formation of FMs and random mistakes.

The relationship between the level of certainty to recollections declared by individuals and their tendency to create FMs remains as appealing as relevant study subject. Presented results disclosed that participants declaring strong feeling of remembering CLs (false memories), were more prone to generate false recollections, compared to less certain individuals. However that nature of this dependency is not linear. Although the experiment was carried out on the relatively small group, results, delivered from varied analysis, strongly suggest that the relationship does exist; differences among people low- and high-certain were significant. Basing on presented results, in general it could be expected, the more certain about accuracy of memory person is, the higher probability of FMs creation. Such results can also be interpreted considering individual differences among memory-cue dependence (Arndt, 2012). This feature is presumably related to cognitive efficiency, mostly among working memory and attention: the more efficient memory attention is, the better memory trace quality and - thereby - smaller necessity searching for external cues to recollect memory content (Dehon, Laroi \& Linden, 2011).
Furthermore, Alberts (2010) noticed negative relationship between declared by participants' certainty to FM and individually measured working memory efficiency, which he attributes to inhibitory control (IC). Participants, who demonstrated efficient IC, were able to block free activation spread among memory network, and decrease FM rates. Such effect could also be explained by the ability to suppress the network activation on the early stage of remembering process, thanks to which they greater ICs show more exact memory.

How to apply described issues to problems of the subjective certainty of false memory traces? In order to provide comprehensive explanation for remembering FM by people strongly convinced of their memory accuracy, we propose combining the memory network activation theory with cognitive functioning explanation, which comprise an efficiency of simple cognitive processes (working memory \& attention) as well as more versatile concepts (i.e. need for external cues that triggers searching for them resulting in increased vulnerability to FM) (Collins and Loftus, 1975; Rumelhart \& Norman, 1975; Reder \& Anderson, 1980; Lorch, 1982; Smith \& Engle, 2008). Also, there is a number of evidence coming from neuropsychological studies to support presented results. For example, Frithsen and Miller (2014) found that the individual efficiency of source- information monitoring (SMF,Johansson and Stenberg, 2002) is related to subjects' ability to distinguish presented from non-presented stimuli (see also: Cansino, Pierre Maquet, Dolan \& Rugg, 2002; Oberauer, 2002; Oberauer, Süß, Willhelm and Witman, 2003; Gamboz et. al., 2010). In line with this, weakly-cognitive functioning individuals remain worse in remembering presented contents and during the memory test tend to declare ,remembering” not only to presented words, but also non-presented lures associated with the main theme of the list. According to obtained data, as well as previous research findings it was established that the integration between false and true memories is initialized immediately after presentation of the stimuli, probably at the stage of encoding memory trace, by incorporation false memories into the semantic network structures. Therefore, when it comes to make decision about the recognition of not presented word, cognitive system is unable to distinguish both traces, because their mental representation exist in a similar way. As a result of entire process completely new, highly available thanks to its semantic proximity to "old" ones -, false memory trace appears (Maciaszek, 2015).

On the other hand, there is a lack of literature putting together research concerning the subjective certainty, declared by participants with the susceptibility to mental distortions, including false memory phenomenon, what makes difficult the interpretation of results unambiguous. Obtained results undoubtedly, however, engage the wider exploration the theme, the minimum of the execution of the replication of the experiment on the greater group and introductions of more precise measuring methods of the 
subjective certainty assessment.

Summary. The formation of false memories as a phenomenon strictly related to the construction of the human mind is being explained by a numerous theories, of which some refer to mechanism of activation spreading along the memory network (Collins \& Loftus, 1975; Rumelhart \& Norman, 1975; Reder \& Anderson, 1980; Lorch, 1982). Many researchers also pay attention to the moderating role of cognitive efficiency, especially among working memory and attention, as they may be related to individual ability to inhibit activation spread. (Johansson and Stenberg, 2002, Mao, Notchboards and Yang, 2010, Alberts, 2010). Notwithstanding, presented research shed some light on existing knowledge, showing on the mechanisms false memories are being created and consolidated in the memory: originated in the semantic storage, recoded and united with the cognitive representation of the situation in the episodic memory. What is more, it turned out that such mechanism evokes strong feeling of remembering false memory traces. Therefore, compelling conclusion appears: not only "remembering" false memories remains above subjects' conscious control, but efforts to control appearance of this phenomenon leads to counter effects.

\section{REFERENCES}

[1] Alberts, J.W., (2010). Inhibitory Control as a Mediator of Individual Differences in Rates of False Memories in Children and Adults. Unpublished dissertation. New Zeland: University of Canterbury.

[2] Tavris, C., \& Aronson, E. (2008). Mistakes were made (but not by me): Why we justify foolish beliefs, bad decisions, and hurtful acts. Houghton Mifflin Harcourt.

[3] Atkins, A. S., Reuter-Lorenz, P. A. (2008). False Working Memories? Semantic Distortion In A Mere 4 Seconds. Memory \& Cognition, 36, 74-81.

[4] Bixter, M., Daniel, F. (2013). Working memory differences in illusory recollection of critical lures. Memory \& Cognition, 41, 716-725.

[5] Brewer, W.F. (1986). What is autobiographical memory? [in]: D.C. Rubin (ed.), Autobiographical memory, New York: Cambridge University Press, 25-49.

[6] Collins, A. M., Loftus E., F. (1975). A spreading-activation theory of semantic processing. Psychological Review, 82, 407-428.

[7] Collins, A. M., Quillian, M .R. (1969). Retrieval time from semantic memory. Journal of verbal learning and verbal behavior, Amsterdam: Elsevier, 240-247.

[8] Deese, J. (1959). On the predictions of occurrence of particular verbal intrusions in immediate recall. Journal of Experimental Psychology, 58(1), 17-22.

[9] Dehon, H. (2012). Illusory recollection: The compelling subjective remembrance of things that never happened. Insights from the DRM paradigm. Psychologica Belgica, 52, 121-149.

[10] Englert, J., Wentura, D. (2016). How "mere" is the mere ownership effect in memory? Evidence for semantic organization processes. Consciousness and Cognition, 46, $71-88$.

[11] Gallo, D. A. (2006). Associate Illusions of Memory: Research on False Memory for Related Events. Associative Illusions of Memory False Memory Research in DRM and Related Tasks. New York: Psychology Press

[12] Gallo, D., A. (2013). Retrieval Expectations Affect False Recollection: Insights from a Criterial Recollection Task Current Directions in Psychological Science, 22, 316-323.

[13] Gardiner, J. M., Java R. I. (1991). Forgetting in recognition memory with and without recollective experience. Memory \& Cognition, 19, 617-623.

[14] Garoff-Eaton, R. J., Slotnick, S. D., Schacter, D. L. (2005). Not All False Memories Are Created Equal: The Neural Basis of False Recognition. Cerebral Cortex, 1-8.

[15] Jacoby, L. L. (1991). A process dissociation framework: Separating automatic from intentional uses of memory. Journal of memory and language, 30(5), 513-541.

[16] Johansson, M., Stenberg, G. (2002). Inducting and reducting false memories: A Swedish Version of the Deese-Roediger-McDermott paradigm. Scandinavian Journal of Psychology, 43, 369-383.

[17] Johansson, M., Stenberg, G. (2002). Inducting and reducting false memories: A Swedish Version of the Deese-Roediger-McDermott paradigm. Scandinavian Journal of Psychology, 43, 369-383.

[18] Johnson, M.K., Hashtroudi, S., Lindsay, D.S. (1993). Source monitoring. Psychological Bulletin, 114, 3-28.

[19] Loftus, E. F. (2003). Our changeable memories: legal and practical implications. Nature, 4, 231-234.

[20] Loftus, E. F. (2005). Planting misinformation in the human mind: A 30-year investigation of the malleability of memory. Learning and Memory, 12, 361-366.

[21] Lorch, R. E. (1982). Priming and search processes in semantic memory: a test of three models of spreading activation. Journal of Verbal Learning and Verbal Behavior, 21, 468-492.

[22] Maciaszek, P. (2013). Fałszywe wspomnienia: jak to sie dzieje, że umysł pamięta coś, czego nie było? Przegląd Filozoficzny - Nowa Seria, 86, 305-326.

[23] Maciaszek, P. (2015). Remembering false memories: on the occurrence of the memory transfer effect in view of confidence judgments. Annales Universitatis Paedagogicae Cracoviensis. Studia Psychologica, 8, 51-64.

[24] Mao, W. B., Wang, L. S., Yang, Z. L. (2010). Modality effect in false recognition: Evidence from Chinese characters. International Journal of Psychology. 45, 4-11

[25] Marchewka, A., Brechmann, A., Nowicka, A., Jednoróg, K., Scheich, H., Grabowska, A. (2008). False recognition of emotional stimuli is lateralised in the brain: An fMRI study. Neurobiology of learning and memory, 280-284. 
[26] Marini, M., Agosta, S., Mazzoni, G., Barba, G. D., \& Sartori, G. (2012). True and False DRM Memories: Differences Detected with an Implicit Task. Frontiers in Psychology, 3, 310.

[27] McDermott, K. B., Roediger, H. R. (1995). Creating False Memories: Remembering Words Not Presented In Lists. Journal of Experimental Psychology: Learning, Memory and Cognition, 21, 803-814.

[28] Mickes, L., Seale-Carlisle, T. M., Wixted, J. T. (2013). Rethinking familiarity: Remember/Know judgments in free recall. Journal of Memory and Language, 68, 333-349.

[29] Monds, L. A., Paterson, H. M., Kemp, R. I., \& Bryant, R. A. (2013). Individual differences in susceptibility to false memories for neutral and trauma-related words. Psychiatry, Psychology and Law, 20(3), 399-411.

[30] Nichols, R. (2014) Not All False Memories Are Created Equal. Niepublikowana praca doktorska. Ann Arbor: University of California.

[31] Olszewska, J., Ulatowska J. (2013). Creating associative memory distortions - a Polish adaptation of the DRM paradigm. Polish Psychological Bulletin, 44, 449-456.

[32] Pohl, R. F. (2004). Cognitive Illusions. Psychology Press: Taylor \& Francis, NY.

[33] Rajaram, S. (1993). Remembering and knowing: Two means of access to the personal past. Memory \& Cognition, 21(1), 89-102.

[34] Reder, L. M., Anderson, J. R. (1980). A partial resolution of the paradox of interference: The role of integrating knowledge. Cognitive Psychology, 12, 447-472.
[35] Roediger III, H. L., \& DeSoto, K. A. (2014). Confidence and memory: assessing positive and negative correlations. Memory, 22(1), 76-91.

[36] Rumelhart, D. E., Norman, D. H. (1975). The active structural network. [in]: D. A. Norman, D. E. Rumelhart (red.). Explorations in cognition, San Francisco: Freeman, 35-64.

[37] Schacter, D. (1996). Searching for memory. The Brain, the Mind and the Past. New York: Basic Books.

[38] Sergi, I. Senese, V. P., Pisani, M., Nigro, G. (2014). Assessing activation of true and false memory traces: A study using the DRM Paradigm. Psychologica Belgica, 54, 171-179.

[39] Slotnik, S. D., Schacter, D. L. (2004). A sensory signature that distinguishes true from false memories. Nature neuroscience, 7, 664-672.

[40] Slotnik, S. D., Schacter, D. L. (2004). The cognitive neuroscience of memory distortion. Neuron, 44, 149-160.

[41] Tse, C., Neely, J. (2005). Assessing activation without source monitoring in the DRM false memory paradigm. Journal of Memory and Language, 53, 532-550.

[42] Tulving, E. (1972). Episodic and semantic memory. Organization of Memory. London: Academic.

[43] Tulving, E. (1985). Memory and consciousness. Canadian Psychologist, 26, 1-12.

[44] Wiesmann, M., Ishai, A. (2008). Recollection and familiarity-based decisions reflect memory strength. Frontiers in Systems Neuroscience, 2, doi:10.3389/neuro.06.001.2008. 